\title{
Awareness Among Dental Undergraduate Students Regarding CAD/CAM Technology-A Survey Report
}

\author{
Sushmita V. Palanisamy ${ }^{1} \quad$ Chethan Hegde $^{1}$ \\ ${ }^{1}$ Department of Prosthodontics and Crown and Bridge, A.B. Shetty \\ Memorial Institute of Dental Sciences, Mangaluru, Karnataka, India
}

\begin{abstract}
Address for correspondence Prof. Dr. Chethan Hegde, Head of the Department, Department of Prosthodontics, A.B. Shetty Memorial Institute of Dental Sciences, Mangaluru 575018, Karnataka, India (e-mail: hedgechethan@yahoo.co.in).
\end{abstract}

\begin{abstract}
Keywords

- CAD/CAM

- undergraduates

- material knowledge

- clinical translation of knowledge

Background Contemporary dentistry is advancing toward computer-aided design/ computer-aided manufacturing (CAD/CAM) technology. But the budding dentists are unaware about the advancement. This survey aims at detecting the level of awareness among the undergraduate students and then correlating those results to modify the future curriculum.

Objective The study aims ( 1 ) to assess the awareness among the dental undergraduate students and (2) to correlate the level of awareness among the third years, final years, and interns.

Sample Selection Study sample consist of 300 students (third year students, final year students, and interns) of A. B. Shetty Memorial Institute of Dental Sciences, Mangalore, Karnataka, India. The information of the survey was collected with the help of a questionnaire.

Results More than $70 \%$ of the students were aware about the basic functioning of CAD/CAM unit and approximately $74 \%$ of the students were unaware about the materials used to fabricate the prosthesis using CAD/CAM technology.
\end{abstract}

\section{Introduction}

The introduction of computer-aided design/computer-aided manufacturing (CAD/CAM) in dentistry began with the work of Dr. Duret. He took digital impression of an abutment tooth after cutting, and then with the help of that impression he fabricated a crown by using numerically controlled machine. ${ }^{1}$

CAD/CAM technology was developed to solve three challenges. The first challenge was to ensure adequate strength of the restoration, especially for posterior teeth. The second challenge was to create restorations with a natural appearance. The third challenge was to make tooth restoration easier, faster, and more accurate. In some cases, CAD/CAM technology provides patients with same-day restorations. ${ }^{2}$

CAD/CAM systems are becoming increasingly popular in dental offices. More than 30,000 dentists around the world own scanning and milling machines; 10,000 of these are in the United States and Canada. Worldwide, more than 15 million chairside economical restoration of esthetic ceramics restorations alone have been completed. ${ }^{2}$ But still the budding dentists are unaware about the advancement. ${ }^{3,4}$ This survey aims at detecting the level of awareness among the undergraduate students studying in A. B. Shetty Memorial Institute of Dental Science, Mangalore, Karnataka, India.

\section{Materials and Methods}

Study sample consists of 300 students (third year students, final year students, and interns) of A.B. Shetty Memorial Institute of Dental Sciences. A self-explanatory questionnaire was given to the undergraduate students to collect the data. Prior to data collection informed consent was taken from all the subjects. Of 300 questionnaires, 200 were received back,
Copyright @2019 Nitte University (Deemed to be University)
License terms

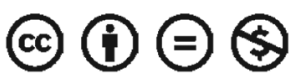


of which 160 were considered valid for the study. Statistical analysis was done using chi-square test. The questionnaires were then grouped into three groups: group 1 (interns), group 2 (final year students), and group 3 (third year students). The following questionnaire was distributed to the students.

1. Are you aware of digital impression?

o Yes

○ No

2. Have you ever seen a CAD/CAM unit?

o Yes

○ No

3. Does your curriculum contain CAD/CAM technology in it?

o Yes

○ No

4. Which among the following materials do you think can be used in CAD/CAM technology?

o Metal

o Zirconium Wax

o All of the above

5. Can complete denture be done using CAD/CAM technology?

o Yes

$\circ$ No

6. Can post and core be done using CAD/CAM technology? o Yes

O No

7. Are you aware of three-dimensional (3D) printing technology?

○ Yes

○ No
8. Do you think if CAD/CAM technology is more precise than conventional procedures?

$\circ$ Yes

O No

9. Which will produce faster restoration: CAD/CAM technology or conventional method?

o CAD/CAM

o Conventional method

10. Elaborate the term CAD/CAM?

\section{Results}

\section{Question 1}

Among the three group, group1 (interns) had slightly higher percentage of awareness about digital impression in comparison to other two groups; however, the difference between the groups were not significant ( $p$-value > 0.005) ( - Fig. 1).

\section{Question 2}

More than $50 \%$ of students in each group gave the wrong elaboration of the term CAD/CAM. Third year students seem to give comparatively more wrong elaboration among the three groups. There is no statistically significant difference between the groups $(p>0.005)$ ( - Fig. 2).

\section{Question 3}

More than $70 \%$ of third and final year students had not seen a CAD/CAM unit, whereas the interns had seen the unit. The difference between the groups was significant $(p<0.005)$. Group 1 (interns) being academically higher ranking than groups 2 and 3, the exposure to newer technology is superior to other two groups ( - Fig. $\mathbf{3}$ ).

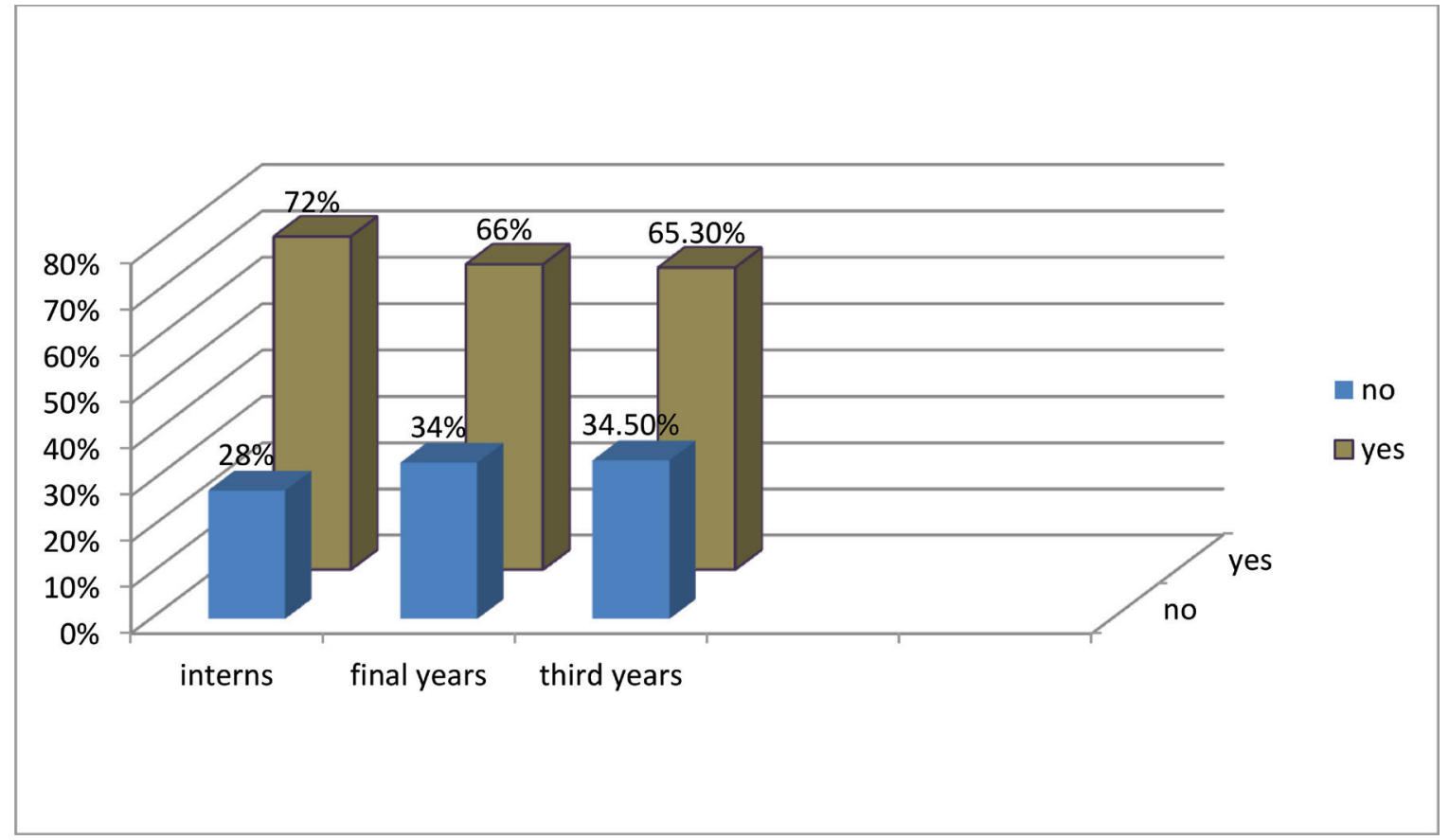

Fig. 1 Are you aware of digital impression? 


\section{Question 4}

In group 3 (third year students), 53\% of students said they have CAD/CAM technology in their curriculum, whereas the percentage decreased from group 2 (final year students) to group 1 (interns). The difference in the group was statistically significant $(p<0.005)$. This indicates that the academics have been improved every year and the students are being made aware about the recent advancement ( - Fig. 4).

\section{Question 5}

More than $70 \%$ of the students in each group said that CAD/ CAM is faster than the conventional method of producing restoration. This shows that the basic knowledge about CAD/
CAM was good in all the groups. There was no statistically significant difference between the groups $(p>0.005)(-$ Fig. 5).

\section{Question 6}

More than $75 \%$ of students in all the three groups said that CAD/CAM is more precise than the conventional method of producing restoration. This in turn shows that the basic knowledge about CAD/CAM was good in all the groups. There was no statistically significant difference between the groups $(p>0.005)(-$ Fig. 6).

\section{Question 7}

More than $70 \%$ of students in all the groups were not aware about the materials used in CAD/CAM technology. This

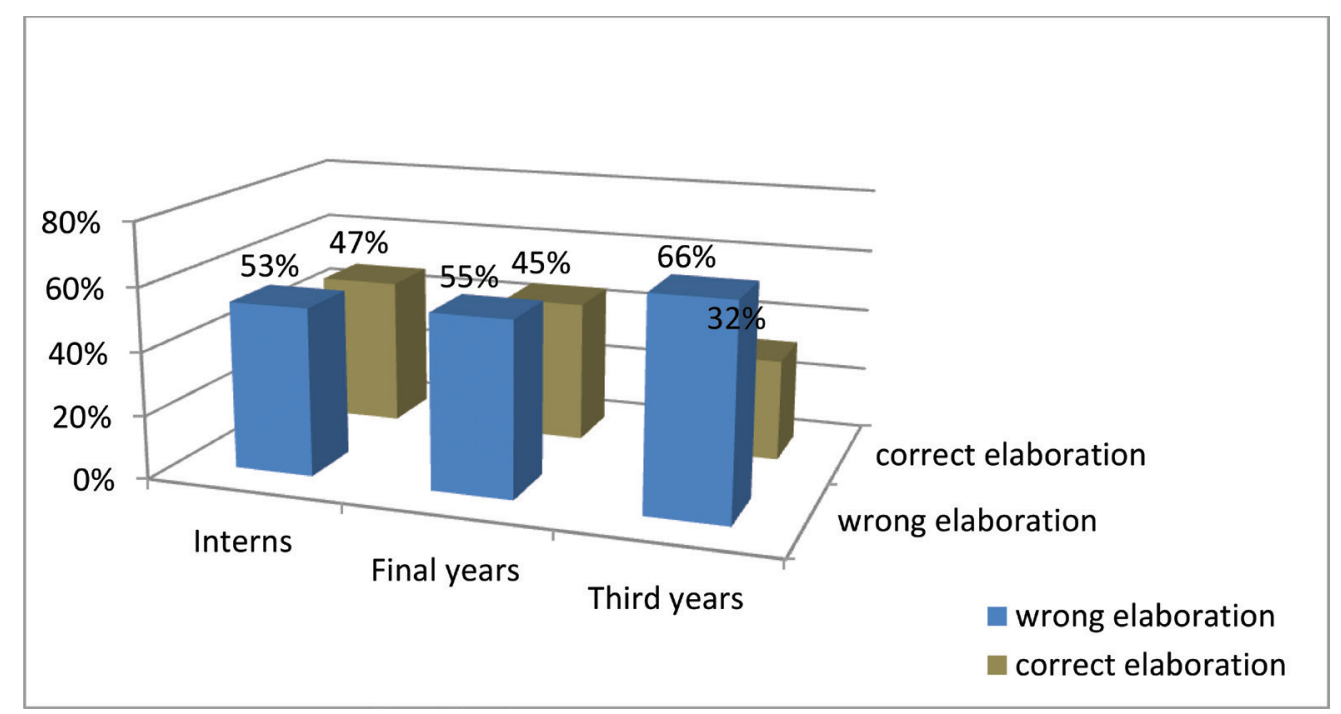

Fig. 2 Elaborate the term computer-aided design/computer-aided manufacturing (CAD/CAM)?

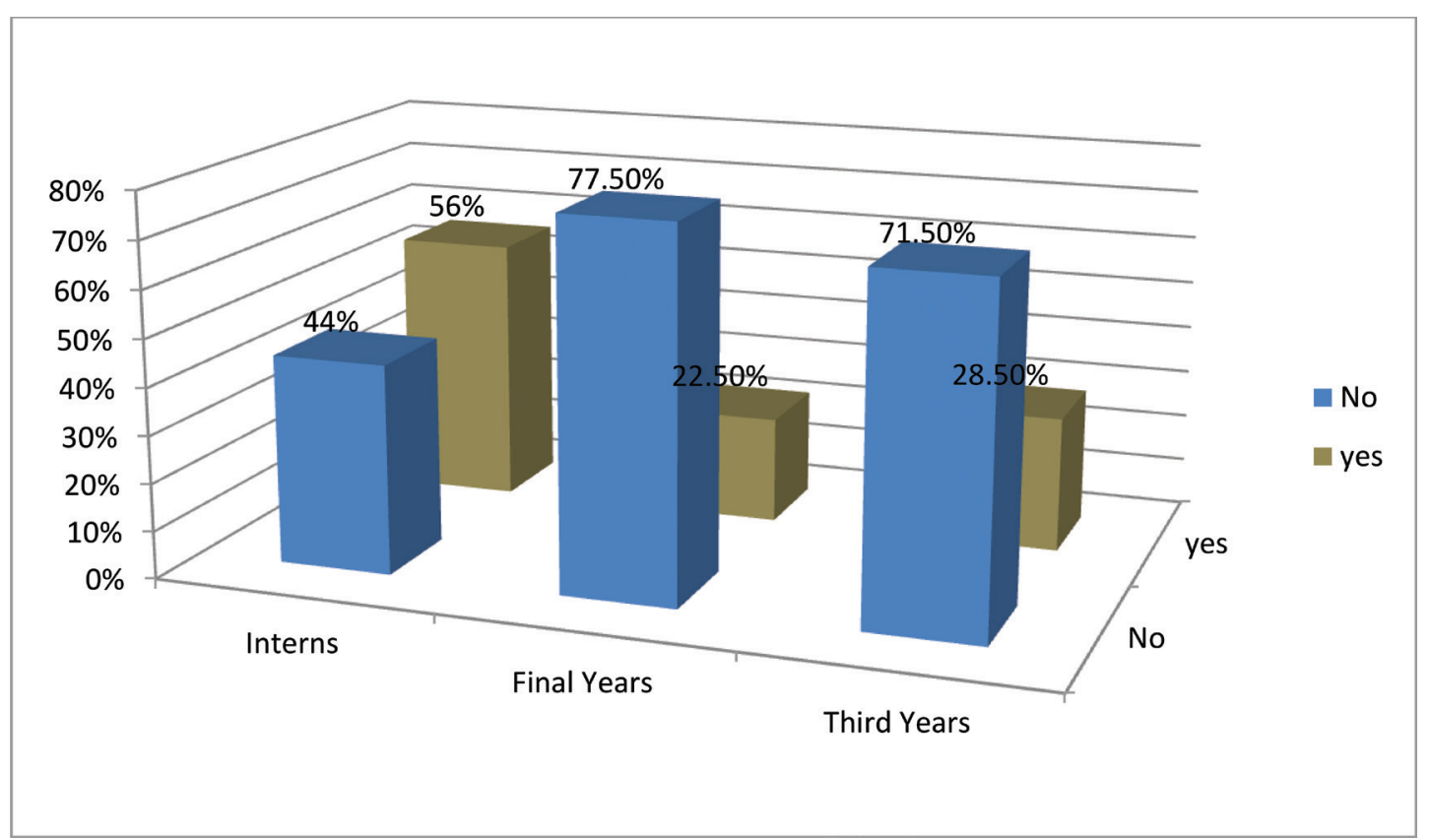

Fig. 3 Have you ever seen a computer-aided design/computer-aided manufacturing (CAD/CAM) unit? 


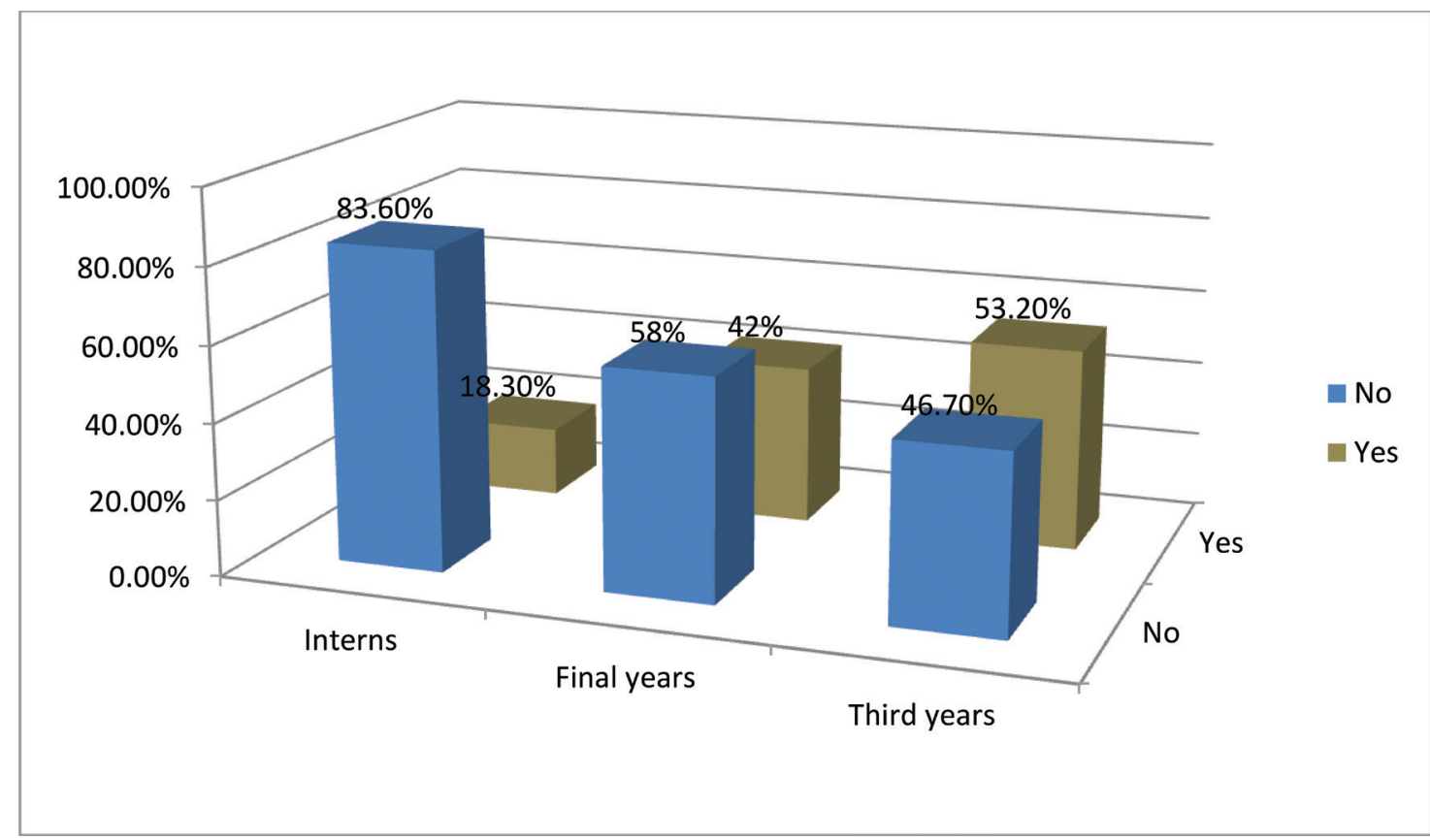

Fig.4 Does your curriculum contain computer-aided design/computer-aided manufacturing (CAD/CAM) technology in it?

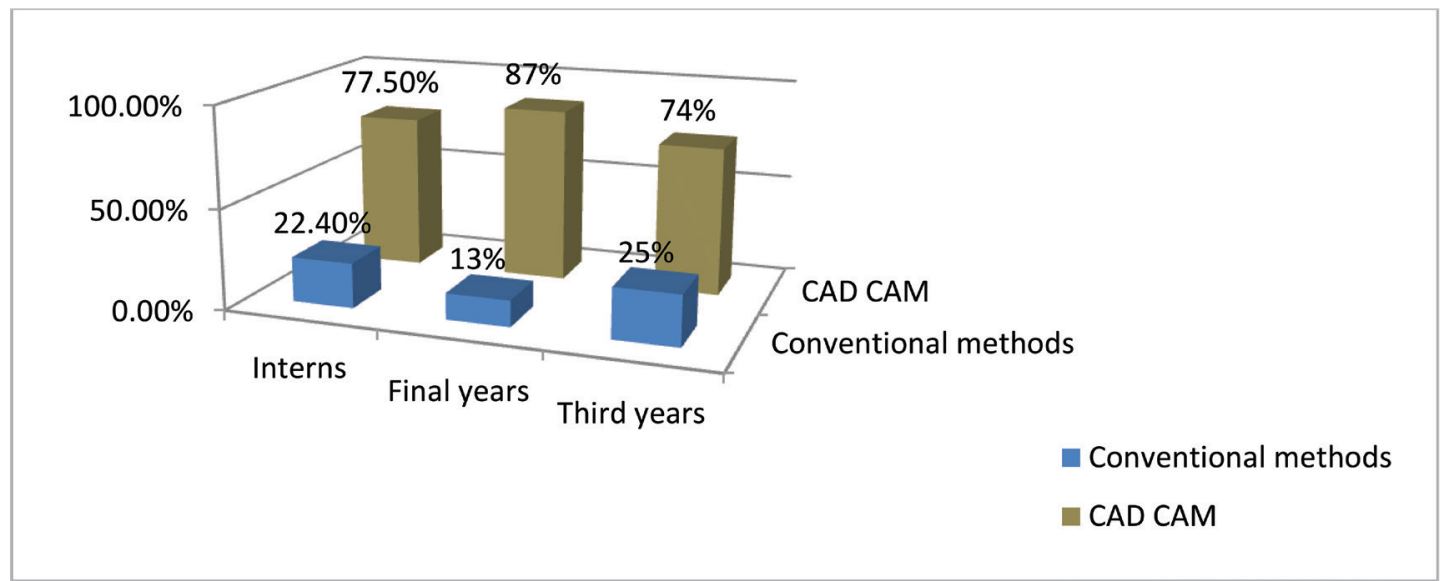

Fig. 5 Which will produce faster restoration computer-aided design/computer-aided manufacturing (CAD/CAM) technology or conventional method?

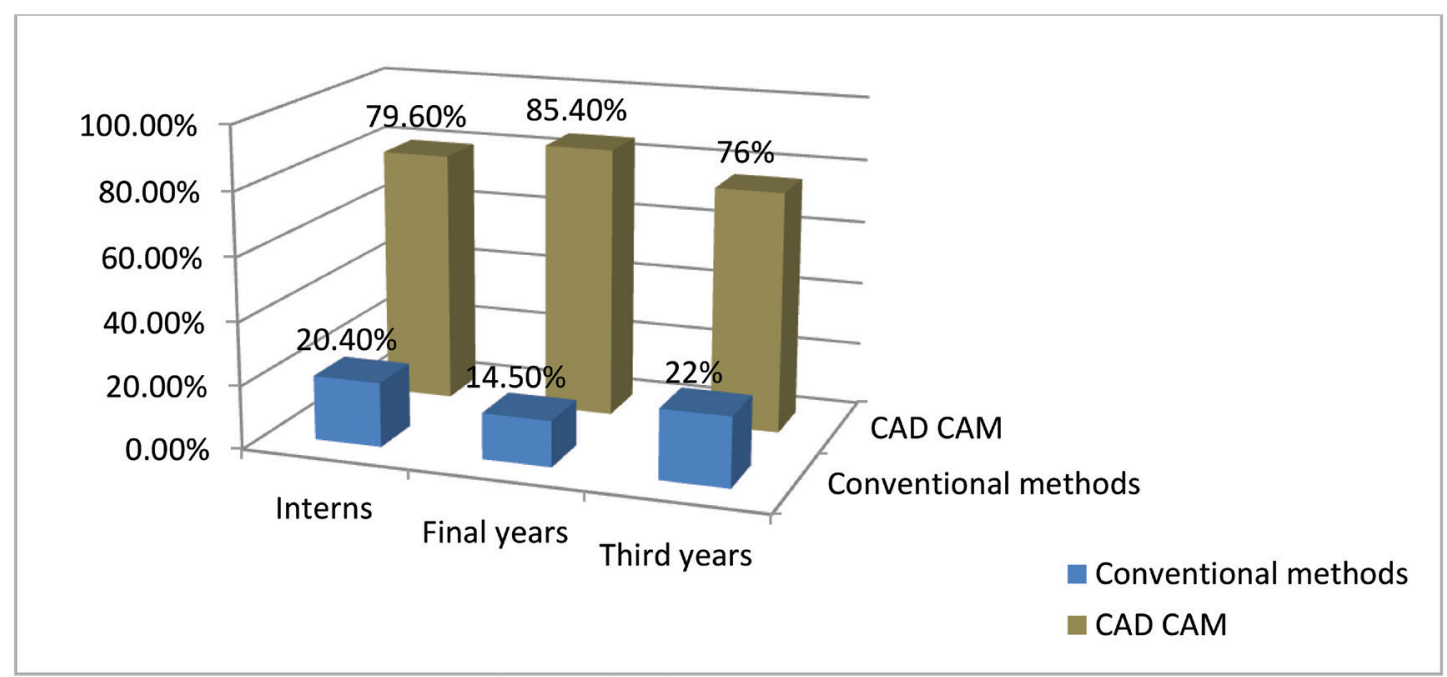

Fig. 6 Do you think if computer-aided design/computer-aided manufacturing (CAD/CAM) technology is more precise than conventional procedures? 
indicates that the depth of knowledge about CAD/CAM in undergraduate level is less. There was no statistically significant difference among the groups ( $p>0.005)(-$ Fig. 7).

\section{Question 8}

Note that $78 \%$ of students in group 1 (interns) were aware about complete denture being fabricated using CAD/CAM technology followed by $74 \%$ of students in group 2 (final year students). Only $26 \%$ of students in group 3 (third year students) were aware of complete denture fabrication using CAD/CAM technology. Statistically significant difference exists among the group $(p<0.005)(-$ Fig. 8 ).

\section{Question 9}

Note that $82 \%$ of students in group 1 (interns) were aware about post and core being fabricated using CAD/CAM technology followed by $74 \%$ of students in group 2 (final year students). Fifty-two percent of students in group 3 (third year students) were aware of post and core fabrication using CAD/ CAM technology. Statistically significant difference exists among the group $(p<0.005)(-$ Fig. 9).

\section{Question 10}

Seventy percent of students in groups 1 and 2 (interns and final year students) were aware of 3D printing technology. Fifty percent of students in group 3 (third year students) were aware of 3D printing technology. There is no statistically significant difference among the group $(p>0.005)(-$ Fig. 10).

\section{Discussion}

Digital dentistry using CAD/CAM technology has become popular in past three decades. It had overcome the disadvantages of the conventional methods especially in terms of quality, labor, and duration. ${ }^{2}$ This is advantageous for both the dentist and patients. A survey by Saponaro et al in 2016 on patient satisfaction with CAD/CAM fabricated complete denture states that $70 \%$ of experienced complete denture patients agreed that their new digital complete dentures were "better" than their previous set of complete dentures. ${ }^{5}$

Being the upcoming field, the undergraduate students should be made aware of CAD/CAM technology academically as well as practically as the future of dentistry is

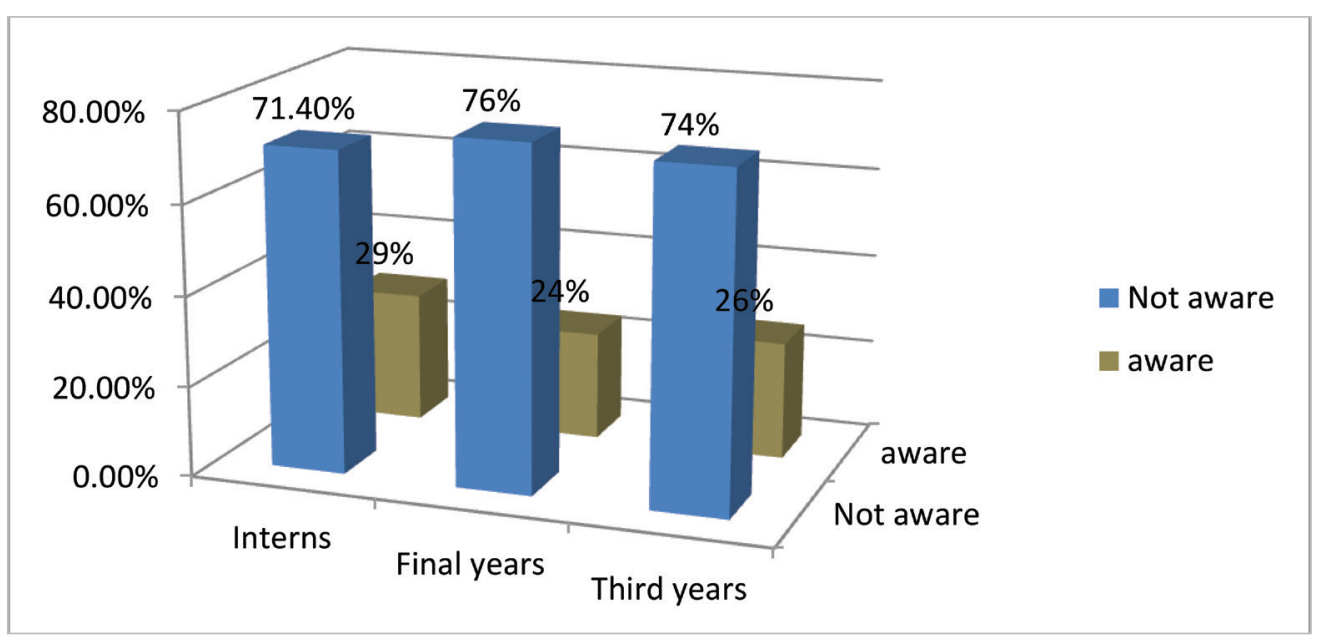

Fig. 7 Which among the following materials do you think can be used in computer-aided design/computer-aided manufacturing (CAD/CAM) technology?

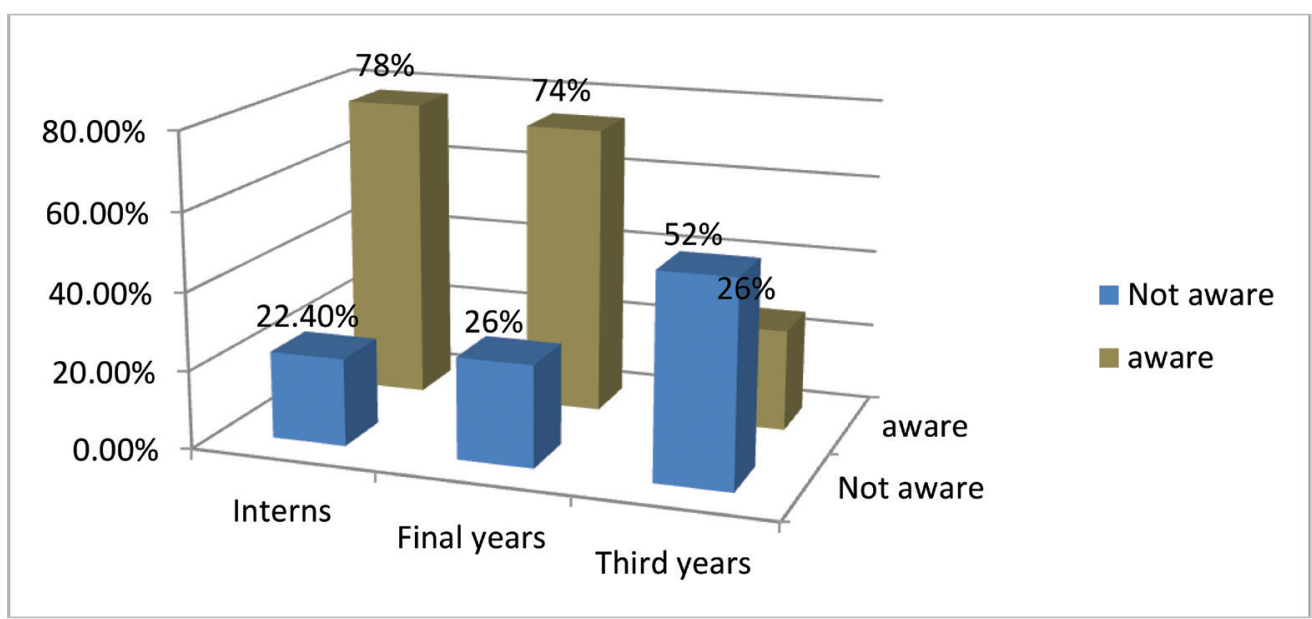

Fig. 8 Can complete denture be done using computer-aided design/computer-aided manufacturing (CAD/CAM) technology? 


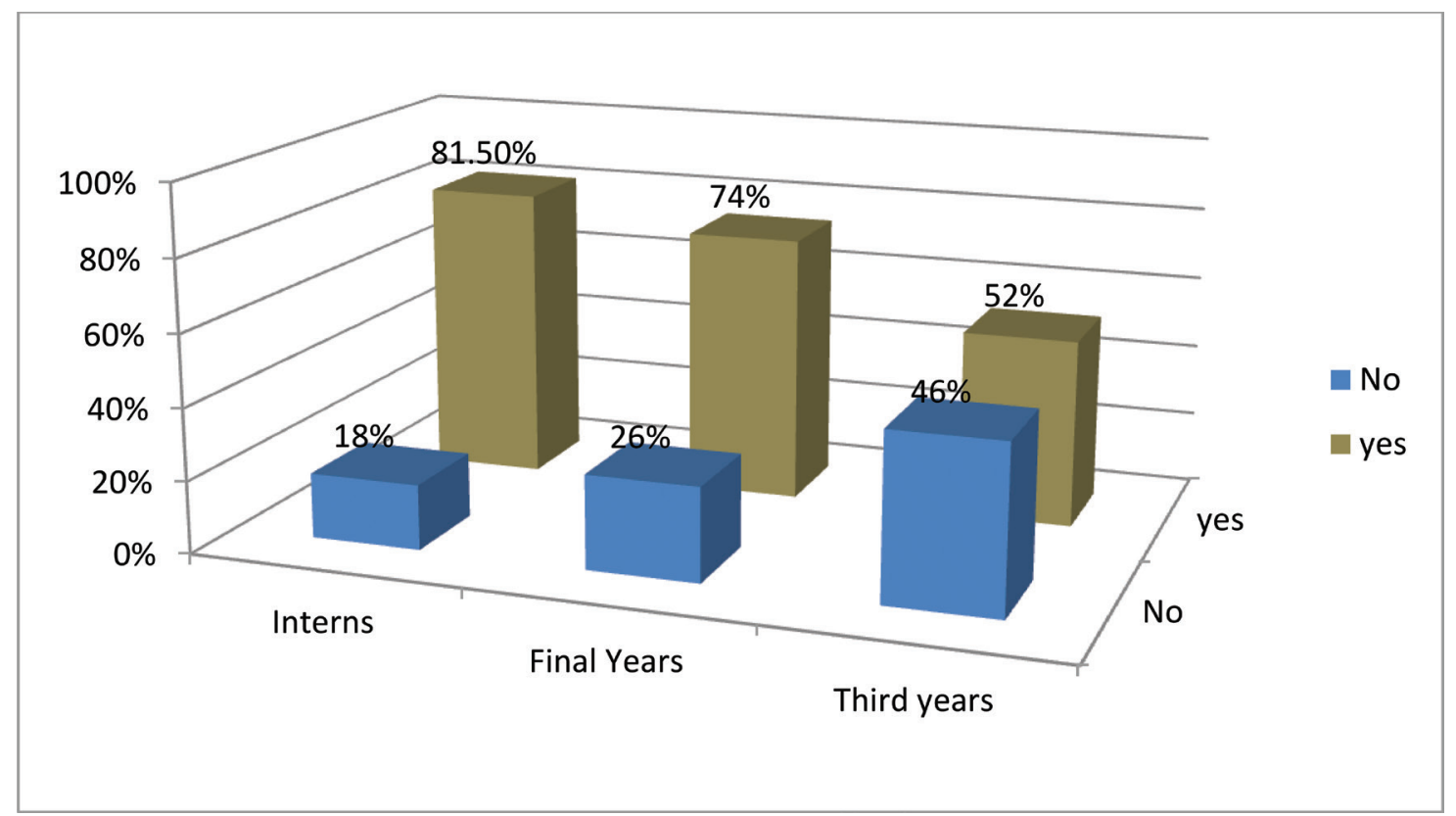

Fig. 9 Can post and core be done using computer-aided design/computer-aided manufacturing (CAD/CAM) technology?

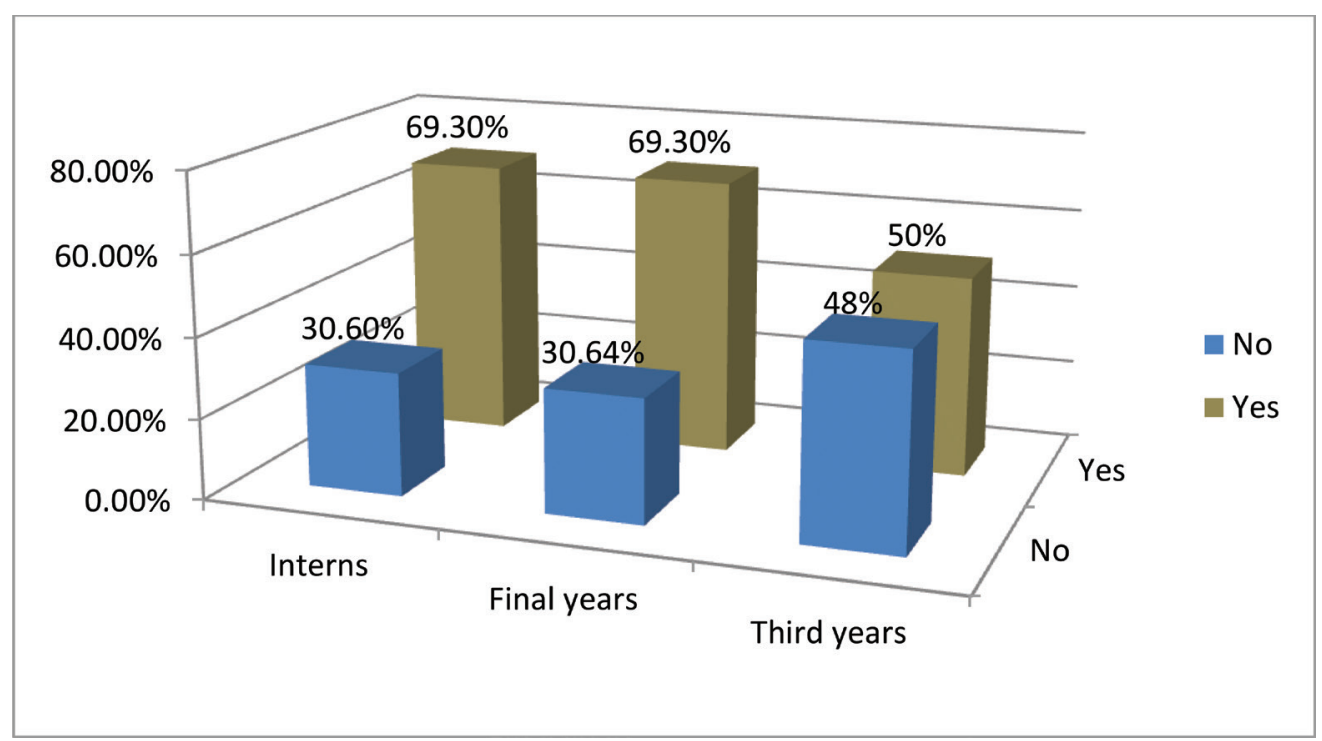

Fig. 10 Are you aware of three-dimensional (3D) printing technology?

going to be digitally driven. Therefore, a questionnaire survey was done to assess the basic knowledge about CAD/CAM technology among undergraduate students. Of the 300 questionnaires given to the undergraduates, 160 questionnaires were considered relevant. The responded questionnaires were grouped into three groups, namely group 1 (interns), group 2 (final year students), and group 3 (third year students). The entire group responded equally for the basic questions asked about CAD/CAM, there was no statistically significant difference between the groups. About $74 \%$ of students were not aware about the materials that can be used to fabricate prosthesis using CAD/CAM technology. This shows that the undergraduates had only shallow knowledge about the technology. This is in accordance to a survey conducted by Kavarthapu and Suresh in $2014 .^{6}$

About $67 \%$ of the students stated that their curriculum does not help them in knowing about CAD/CAM technology and only $35 \%$ of the undergraduate students had seen a CAD/ CAM unit. This shows the lack of practical knowledge and lack of clinical translation of knowledge among the undergraduate students. Overall, the knowledge about CAD/CAM in undergraduates had improved, but they should be made aware about the clinical usage of it to make them equipped to meet the future digital dentistry. 


\section{Conclusion}

Based on the results of the study, it is observed that the students are aware about the digital technologies but they lack the clinical knowledge which will only be imparted through hands on experience. Hence, the curriculum should be modified periodically to incorporate the newer advances which will in turn improve the clinical practice of the students.

\section{Conflict of Interest}

None.

\section{References}

1 Aslam K, Nadim R. A review on CAD CAM in dentistry. JPDA 2015;24(03):112
2 Davidowitz G, Kotick PG. The use of CAD/CAM in dentistry. Dent Clin North Am 2011;55(3):559-570,ix

3 Chatham C, Spencer MH, Wood DJ, Johnson A. The introduction of digital dental technology into BDS curricula. Br Dent J 2014;217(11):639-642

4 Popa D, Burde A, Constantiniuc M, Ioana R, Bordea B, Compian RS. Students' attitude towards dental CAD/CAM systems: a questionnaire study. Am Sci Res J Eng Technol Sci 2015;14(3):250-254

5 Saponaro PC, Yilmaz B, Johnston W, Heshmati RH, McGlumphy EA. Evaluation of patient experience and satisfaction with CAD-CAM-fabricated complete dentures: a retrospective survey study. J Prosthet Dent 2016;116(4):524-528

6 Kavarthapu A, Suresh V. CAD/CAM: a perspective of dental undergraduate. IOSR J Dental Med Sci 2014;13(1):30 